\title{
Clinical experience with an oral anticoagulant in children
}

\author{
UGO CARPENTIERI, QUANG X. NGHIEM, and LEONARD C. HARRIS \\ From the Department of Pediatrics, University of Texas Medical Branch, Galveston, Texas, U.S.A.
}

\begin{abstract}
Carpentieri, U., Nghiem,Q.X., and Harris, L. C. (1976). Archives of Disease in Childhood, 51, 445. Clinical experience with an oral anticoagulant in children. Nineteen cardiac patients were given warfarin sodium to prevent thrombosis and embolism. Empirical dosage resulted in long hospital stays to obtain a stable therapeutic prothrombin time. Using a dosage of $0.5-0.7 \mathrm{mg} / \mathrm{kg}$, therapeutic levels were achieved in a much shorter time. When prothrombin time was excessive, it was successfully reduced with vitamin $\mathrm{K}$ or plasma. A haematoma in one case and haematuria in another were easily controlled.

Warfarin sodium appears to be appropriate and effective for children requiring anticoagulants within the above dosage limits and with meticulous follow-up.
\end{abstract}

Warfarin anticoagulation has been used extensively in adults. In children there has been limited use of this agent and we were unable to find published reports about dosage in this age group. Heparin has been used in children for disseminated intravascular coagulation, but its use under these circumstances is short lived and usually related to an acute episode. In recent years indications for long-term anticoagulation have become more common, e.g. idiopathic nonobstructive cardiomyopathy and in patients in whom cardiac valves have been replaced by prosthetic valves.

The most important problems in anticoagulation therapy of children are the choice of the anticoagulant, its efficiency, dosage, and possible complications secondary to children's routine activity. This paper reports the experience with the use of warfarin in children and adolescents.

\section{Material and methods}

Since 1962, the authors have given anticoagulant to 19 patients under the age of 18 years. The Table gives cases according to indications for anticoagulant therapy, primary diagnoses, valves replaced, number of admissions to hospital necessary for effective anticoagulation, its complications, and years of follow up.

Crystalline sodium warfarin (Coumadin) was used in every case, with a dosage range of $0 \cdot 3-1 \cdot 0 \mathrm{mg} / \mathrm{kg}$. The total loading dose of $10-40 \mathrm{mg}$ was followed by daily maintenance of $15-25 \%$ of loading dose $(2 \cdot 5-10 \mathrm{mg})$.

Received 9 September 1975.
The effects were assessed by daily prothrombin time. A prothrombin time of $1 \cdot 5-2 \cdot 5$ times the control was considered to be therapeutic. Adjustment of the maintenance dose was made when necessary with changes of $1 \cdot 0-2 \cdot 0 \mathrm{mg}$ daily or on alternate days. Treatment was started on the second or third day after surgery or the estimated time of embolism. In the 4 patients with cerebral embolism treatment was begun after 3 to 4 weeks in order to avoid the possible danger of transforming a white into a red thrombus.

The first 15 patients were given empirical doses, and the remaining 4 patients (Cases 16 to 19) were given dosages as indicated in the Fig. $(0.5-0.7 \mathrm{mg} / \mathrm{kg})$.

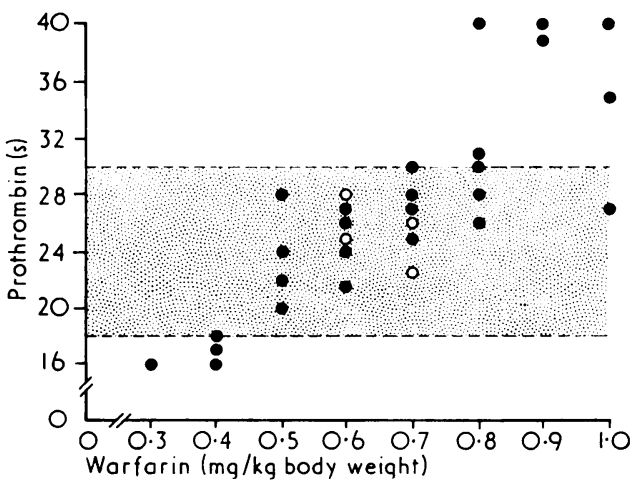

FIG.-Doses of warfarin versus prothrombin time. Therapeutic prothrombin time (grey zone) obtained with 0.5-0.7 $\mathrm{mg} / \mathrm{kg}$. indicate 15 initial and 11 repeated loading doses; 0 represent the 4 patients treated with dosage suggested by the previous 15 cases. 
Indications, complications and follow-u踣of

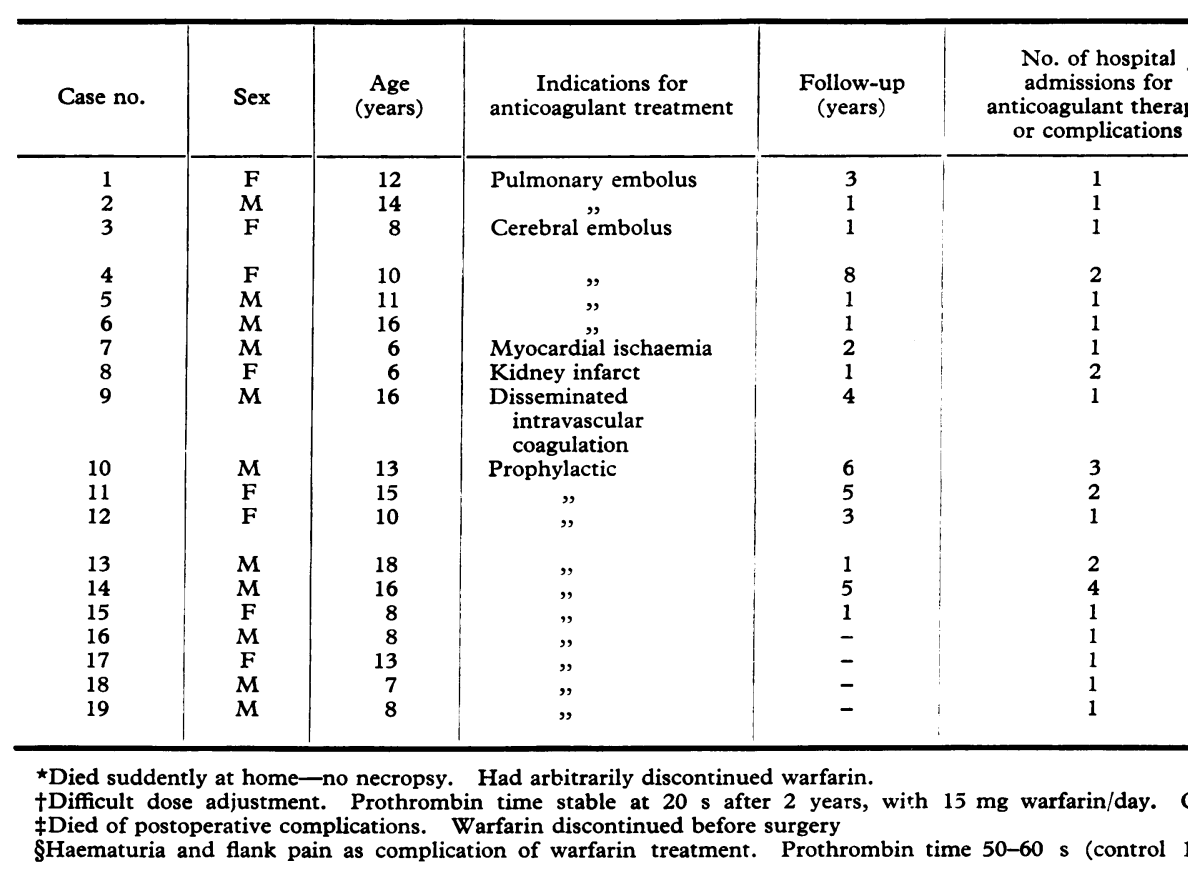

When stable therapeutic prothrombin time was reached and all the other clinical problems were resolved, the patients were discharged and followed up monthly by their physician or by our clinic.

\section{Results}

The Fig. shows prothrombin time 36 hours after a loading dose, against loading doses expressed in $\mathrm{mg} / \mathrm{kg}$ body weight. The therapeutic prothrombin time was always achieved at about $36-48$ hours and was obtained with a dosage of between 0.5 and $0.7 \mathrm{mg} / \mathrm{kg}$. In 7 patients warfarin was discontinued because the prothrombin time had exceeded 30 seconds. Treatment was restarted with a lower loading dose. In 3 patients with a prothrombin time of $40 \mathrm{~s}$, vitamin $\mathrm{K}$ was given. In another case, vitamin $\mathrm{K}$ was ineffective and prothrombin time was restored to normal by giving fresh plasma IV.

In the first 15 cases an average of four adjustments (range 3-7) were made in warfarin maintenance dosage before stabilization of the desired prothrombin time. The average time taken to reach this dosage was 20 days (range 8-70 days). Using the Fig. as a guide, a stable therapeutic prothrombin time was reached in the last 4 patients of the Table in an average time of only 6 days. Two complicated cases not included in the Fig. are summarized in the Table (Cases 10 and 14).

Warfarin dosage was reduced by $50 \%$ in 4 patients who had teeth extractions. No rebound hypercoagulability was observed, but in these cases it was later necessary to readminister a loading dose of warfarin because the optimal prothrombin time could not be achieved by continuing the previous maintenance dose. No thromboembolic accidents occurred during the warfarin treatment. In Case 8 necropsy examination showed no recent areas of infarction or bleeding.

\section{Discussion}

Anticoagulant treatment with warfarin sodium may be indicated to prevent thrombi occurring after a prosthetic valve insertion or in cases of idiopathic nonobstructive cardiomyopathy. In adults, extensive reviews of anticoagulation therapy with coumarin congeners have been published (Alexander, 1962; Aggeler and O'Reilly, 1966; O'Reilly and Aggeler, 1970; Wright, 1969; Wessler, 1974) since the successful treatment of pulmonary embolism in 1960 (Barritt and Jordan, 1960). 
anticoagulant therapy with warfarin in children

\begin{tabular}{|c|c|c|}
\hline Primary diagnosis & $\begin{array}{l}\text { Valve(s) } \\
\text { replaced }\end{array}$ & Comments \\
\hline $\begin{array}{l}\text { Mitral insufficiency } \\
\text { Mitral and tricuspid insufficiency } \\
\text { Mitral and tricuspid insufficiency } \\
\text { Aortic insufficiency } \\
\text { Aortic insufficiency } \\
\text { Idiopathic nonobstructive cardiomyopathy } \\
\text { Mitral insufficiency } \\
\text { ", } \\
\text { ", }\end{array}$ & $\begin{array}{l}\text { Mitral } \\
\text { None } \\
\text { Mitral \& } \\
\text { tricuspid } \\
\text { Mitral } \\
\text { Mitral } \\
\text { Mitral } \\
\text { None } \\
\text { None } \\
\text { Mitral, } \\
\quad \text { tricuspid, } \\
\text { aortic } \\
\text { Mitral } \\
\text { Mitral } \\
\text { Mitral \& } \\
\text { tricuspid } \\
\text { Aortic } \\
\text { Aortic } \\
\text { None } \\
\text { Mitral } \\
\quad \text {, } \\
\text { " } \\
\text {, }\end{array}$ & $\begin{array}{l}\ddagger \\
\S \\
\star \\
\text { Cases } 16 \text { to } 19 \\
\text { treated with the } \\
\text { suggested dose of } \\
\text { warfarin (see text) }\end{array}$ \\
\hline
\end{tabular}

periocular haematoma, resolved without treatment and without discontinuing warfarin.

unrelated to warfarin dosage. All lab tests normal. No symptoms when prothrombin time $1 \cdot 5-2$ times the control.

However, we could find no references to long-term anticoagulation with such drugs in children.

In this study the only drug used for anticoagulation was warfarin and no attempt was made to compare its effect with other anticoagulants. Warfarin sodium is a water soluble derivative of coumaric acid. Absorbed completely in the small intestine, it is loosely bound to albumin and transported in the blood. It is degraded in the liver and its degradation products, also bound to albumin, are excreted in the urine. Warfarin competes with vitamin $\mathrm{K}$, which is necessary for the synthesis of factors II, VII, IX, and $\mathrm{X}$ of the coagulation cascade. Acute administration of warfarin lowers these factors. Factor VII is the most sensitive of all (Coon and Willis, 1970; Deykin, 1970).

Different adult dosages have been advised by various authors. Most recommend a large enough sodium warfarin dose to prolong and maintain prothrombin time between 1.5 and 2.5 times the control (Deykin, 1970; Koch-Weser, 1974). In this study the range appeared to be both safe and effective with the exception of one patient with haematuria. In this instance prothrombin time had to be restricted to two times the control.

A loading dose was given in all our cases because in the authors' experience therapeutic prothrombin time could never be achieved with maintenance doses only. This differs from other results (Deykin, 1970; O'Reilly and Aggeler, 1968). It is evident from our experience and of others (Alexander, 1962; O'Reilly and Aggeler, 1970; Wessler, 1974; Coon and Willis, 1970) that the dose of warfarin must be adjusted individually and precautions taken to avoid overdosage. The present study suggests that therapeutic prothrombin time can be attained by a warfarin loading dose of $0.5-$ $0.7 \mathrm{mg} / \mathrm{kg}$. Overdosage in our experience caused no serious complications and excessively prolonged prothrombin time was easily corrected with vitamin K.

In the cases in which warfarin dosage was lowered or discontinued there was no rebound phenomenon. This is at variance with data from other sources (A. Starr and Edwards Laboratories, personal communications, 1972). It is also the authors' impression that suspension of treatment appears to be unnecessary during minor surgery, when possible thrombosis or embolism may be a greater threat to life than warfarin overdosage.

A negligent patient taking erratic or incorrect doses, widely spaced follow-up visits, and improper 
evaluation of individual response to the drug may prevent a proper therapeutic level of prothrombin time being reached. It is necessary to check the prothrombin time daily during the period of adjustment and every 2-3 weeks when the optimal dose has been chosen. Frequent visits help to educate the patient and provide psychological support.

On the basis of the present observations the possibility of trauma does not seem to be a firm contraindication to anticoagulant treatment. Only two possible complications could be ascribed to warfarin. One of these was in a child with a large post-traumatic periocular haematoma which resolved spontaneously and without discontinuing warfarin. The other was a patient with flank pain and haematuria, without a history of trauma.

Other medications administered to patients in this study included antibiotics, digitalis, diuretics, aspirin, other analgesics, quinidine, spironolactone, ferrous sulphate, and reserpine. Many authors describe interaction of some of these drugs with warfarin, but in this series no interference could be shown (Collaborative Drug Surveillance Program, 1972; Coon and Willis, 1970; Koch-Weser, 1974; Kazmier and Spittell, 1970; Aggeler et al., 1967; Robinson and Sylwester, 1970; KochWeser and Sellers, 1971).

Finally, it is possible to decrease the hospital stay and expenses by using a therapeutic dosage of warfarin from the onset. This is indicated by the 4 patients successfully treated with doses of warfarin calculated as illustrated in the Fig. In these 4 cases stable therapeutic prothrombin times were attained in an average period of 6 days, compared with a previous average of 20 days.

\section{REFERENCES}

Aggeler, P. M., and O'Reilly, R. A. (1966). The pharmacological basis of oral anticoagulant therapy. Thrombosis et diathesis. Haemorrhagica, Suppl. 21, 227.

Aggeler, P. M., O'Reilly, R. A., Leong, L., and Kowitz, P. E. (1967) Potentiation of anticoagulant effect of warfarin by phenylbutazone. New England fournal of Medicine, 276, 496.

Alexander, B. (1962). Anticoagulant therapy with coumarin congeners. American fournal of Medicine, 33, 679.

Barritt, D. W., and Jordan, S. C. (1960). Anticoagulant drugs in the treatment of pulmonary embolism: a controlled trial. Lancet, 1, 1309.

Coon, W. W., and Willis, P. W. (1970). Some aspects of the pharmacology of oral anticoagulants. Clinical Pharmacology and Therapeutics, 11, 312.

Deykin, D. (1970). Warfarin therapy. New England fournal of Medicine, 283, 691 and 801.

Collaborative Drug Surveillance Program, Boston (1972). Interaction between chloral hydrate and warfarin. New England Fournal of Medicine, 286, 53.

Kazmier, F. J., and Spittell, J. A. (1970). Coumarin drug interactions. Proceedings of the Staff Meetings of the Mayo Clinic, 45, 249.

Koch-Weser, J. (1974). Bioavailability of drugs. New England fournal of Medicine, 291, 233.

Koch-Weser, J., and Sellers, E. M. (1971). Drug interactions with Coumarin anticoagulants. New England fournal of Medicine, 285, 487 and 547.

O'Reilly, R. A., and Aggeler, P. M. (1968). Studies on Coumarin anticoagulant drugs: initiation of warfarin therapy without a loading dose. Circulation, 38, 169.

O'Reilly, R. A., and Aggeler, P. M. (1970). Determinants of the response to oral anticoagulant drugs in man. Pharmacological Reviews, 22, 35.

Robinson, D. S., and Sylwester, D. (1970). Interaction of commonly prescribed drugs and warfarin. Annals of Internal Medicine, $72,853$.

Wessler, S. (1974). Anticoagulant therapy-1974. Fournal of the American Medical Association, 228, 757.

Wright, I. S. (1969). Recent developments in antithrombotic therapy. Annals of Internal Medicine, 71, 823.

Correspondence to Dr. Ugo Carpentieri, Department of Pediatrics, University of Texas Medical Branch, Galveston, Texas 77550, USA. 